\title{
An efficient method for visualization and growth of fluorescent Xanthomonas oryzae pv. oryzae in planta Sang-Wook Han ${ }^{\dagger}$, Chang-Jin Park ${ }^{\dagger}$, Sang-Won Lee ${ }^{\dagger}$ and Pamela C Ronald*
}

Address: Department of Plant Pathology, University of California, One Shields Avenue, Davis, CA., 95616, USA

Email: Sang-Wook Han - swhan@ucdavis.edu; Chang-Jin Park - cjppark@ucdavis.edu; Sang-Won Lee - drlee@ucdavis.edu; Pamela C Ronald* - pcronald@ucdavis.edu

* Corresponding author †Equal contributors

Published: 30 September 2008

BMC Microbiology 2008, 8:164 doi:10.1 |86/|47|-2/80-8-164

This article is available from: http://www.biomedcentral.com//47I-2/80/8//64

(C) 2008 Han et al; licensee BioMed Central Ltd.

This is an Open Access article distributed under the terms of the Creative Commons Attribution License (http://creativecommons.org/licenses/by/2.0), which permits unrestricted use, distribution, and reproduction in any medium, provided the original work is properly cited.
Received: 25 April 2008

Accepted: 30 September 2008

\begin{abstract}
Background: Xanthomonas oryzae pv. oryzae, the causal agent of bacterial blight disease, is a serious pathogen of rice. Here we describe a fluorescent marker system to study virulence and pathogenicity of $X$. oryzae pv. oryzae.

Results: A fluorescent $X$. oryzae pv. oryzae Philippine race 6 strain expressing green fluorescent protein (GFP) (PXO99 ${ }_{\text {GFP }}$ ) was generated using the $\mathrm{gfP}$ gene under the control of the neomycin promoter in the vector, $\mathrm{PPneo-g} \mathrm{P}$. The $\mathrm{PXO} 99_{\mathrm{GFP}} \mathrm{strain}$ displayed identical virulence and avirulence properties as the wild type control strain, PXO99. Using fluorescent microscopy, bacterial multiplication and colonization were directly observed in rice xylem vessels. Accurate and rapid determination of bacterial growth was assessed using fluoremetry and an Enzyme-Linked ImmunoSorbant Assay (ELISA).
\end{abstract}

Conclusion: Our results indicate that the fluorescent marker system is useful for assessing bacterial infection and monitoring bacterial multiplication in planta.

\section{Background}

Xanthomonas oryzae pv. oryzae, a yellow-pigmented Gramnegative bacterium, is the causal agent of bacterial blight disease of rice (Oryzae sativa L.) plants. X. oryzae pv. oryzae infection can cause yield loss of up to $50 \%$ in tropical Asia [1]. X. oryzae pv. oryzae infects rice leaves through natural openings such as hydathodes and/or wounded sites and then primarily colonizes the vascular tissues by propagating in the xylem. Increased extracellular polysaccharide secretion accompanies bacteria growth, eventually causing a block in the vascular system [2]. The early symptoms therefore start with wilting in the infected leaves and enlargement in length and width of the legions of leaf blight [3]. As the symptom progress, severe necrosis occurs along the interveinal regions. Eventually, the whole leaf becomes whitish and greyish, and then dies $[2,4]$. Over the last few decades, the challenge in elucidating biological phenomena has been met by advances in techniques, which have accelerated our understanding of biological events. In particular, useful tools have been developed to evaluate cellular dynamics in vivo. One of the best examples of a technique that has facilitated cellbased studies is marker systems that use fluorescent proteins (FPs). Since the green fluorescent protein (GFP) was first discovered from the jellyfish Aequorea victoria in 1962 [5], various types of FPs, including red, yellow, and cyanine fluorescent proteins, have been developed and used in fields such as biophysics, biochemistry, and plant pathology [6-8]. The proteins are stable [9], non-species specific $[10,11]$, and have no requirement of specific sub- 
strate [11]. Therefore, labelling a specific target protein with a FP is a powerful molecular tool for a cell biology study since it provides the ability to visualize, track, and quantify targets in living cells with high spatial and temporal resolution essential features for understanding biology systems [8]. In addition, bimolecular fluorescence complementation (BiFC) analysis using split-FP systems has been successfully applied to determine protein-protein interactions in planta as well as in animals [12,13]. Recently, FPs have been used for monitoring living organisms such as Lactobacillus sakie, Pseudomonas syringae, $X$. axonopodis pv. dieffenbachiae, and Xylella fastidiosa in their hosts [14-17].

To determine virulence and pathogenicity of bacterial pathogens in plant-microbe interactions, researchers typically quantify bacterial multiplication in planta by counting the number of bacterial colonies in plate assays of leaf extracts $[18,19]$. This method consists of leaf harvesting, tissue maceration, colony plating, incubating, and counting of bacterial cells. These methods are time-consuming and labour intensive, especially for slow-growing bacteria like $X$. oryzae pv. oryzae. In addition, the results frequently show large amounts of variation depending on experimental conditions.

Here, we provide an improved method for the study of $X$. oryzae pv. oryzae using a fluorescent marker system. It not only eliminates many of the difficulties of conventional methods but also allows for reliable and rapid monitoring of bacteria in planta prior to the formation of symptoms.

\section{Results and discussion}

Generation of $X$. oryzae pv. oryzae expressing GFP

$X$. oryzae pv. oryzae Philippine race 6 (PXO99) carrying the $g f p$ gene was generated using pPneo- $g f p$, which is a new construct based on the broad-host-range probe vector, pPROBE-gfp [20] and the pML122 vector [21]. The pPROBE- $f f p$ plasmid was previously used as a marker to assess expression of genes of interest in Xyllela festidosa and $X$. campestris pv. campestris [22]. The neomycin promoter in pML122 was successfully used for protein expression in $X$. oryzae pv. oryzae [23]. To generate a plasmid, pPneo-gfp, which is approximately 400 nucleotides long and contains the neomycin promoter, was taken from the pML122 plasmid and ligated into a pPROBE-gfp vector. The modified construct was introduced into PXO99 wild type strain and transformants were selected on peptone sucrose agar (PSA) plate containing kanamycin $(50 \mu \mathrm{g} /$ $\mathrm{ml}$ ) for selection of pPneo-gfp. Expression of GFP in the transformants was tested by Western-blot analysis using an anti-GFP antibody (data not shown). X. oryzae pv. oryzae carrying pPneo-gfp (PXO99 ${ }_{\mathrm{GFP}}$ ) showed strong fluorescence (Fig. 1). Our results demonstrate that the PXO99 ${ }_{\mathrm{GFP}}$ strain carrying the pPneo-gfp vector constitu-

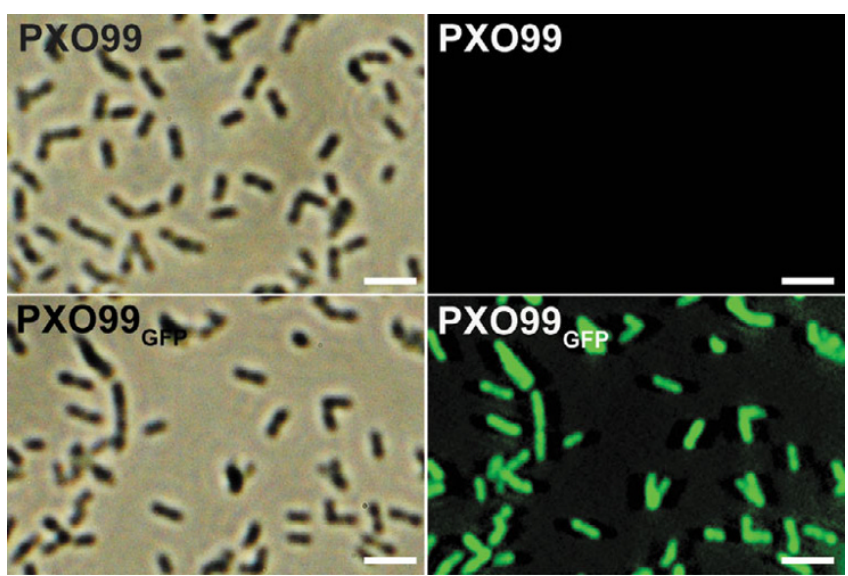

\section{Figure I}

Observation of Xanthomonas oryzae pv. oryzae carrying green fluorescence protein. $\mathrm{PXO} 99_{\mathrm{GFP}}$ selected on PSA plates containing kanamycin $(50 \mu \mathrm{g} / \mathrm{ml})$ were cultured with $5 \mathrm{ml}$ PS broth medium, harvested with centrifugation, washed with distilled water three times, re-suspended with $10 \mu \mathrm{l}$ of autoclaved water, and then observed with microscope equipped with a fluorescein isothiocyanate filter (excitation filter, 450 to $490 \mathrm{~nm}$; emission filter, $520 \mathrm{~nm}$; dichroic mirror, $510 \mathrm{~nm}$ ). Lefts are images with PXO99 wild type (up) and PXO99 ${ }_{\text {GFP }}$ (down) strains under bright light. Rights are the images of the bacteria with illumination of UV. The bars in the left bottom of each image indicate $5 \mu \mathrm{m}$.

tively and strongly expresses GFP in X. oryzae pv. oryzae, suggesting that the marker system might be applied to study plant-microbe interactions in planta.

\section{The PXO99 ${ }_{\text {GFP }}$ strain is useful for studies of $X$. oryzae pv. oryzae pathogenesis}

First, we examined whether the pPneo-gfp vector/plasmid had an affect on the pathogenicity and virulence of $X$. oryzae pv. oryzae in rice. The leaves from japonica rice varieties Taipei 309 (TP309, susceptible to PXO99) and a transgenic line of TP309 expressing the XA21 resistance protein (TP309-XA21, resistant to PXO99) were inoculated with the PXO99 or PXO99 ${ }_{\mathrm{GFP}}$ strains using the scissor clipping method [24]. The typical inoculation symptoms were consistent between the PXO99 and PXO99 ${ }_{\text {GFP }}$ strains. In the susceptible line (TP309), lesions that developed were approximately 17 to $23 \mathrm{~cm}$ in length at $12 \mathrm{DPI}$, while lesions were less than $1 \mathrm{~cm}$ in the resistant line (TP309-XA21). (Fig 2A) These results suggest that pPneo-gfp introduction into the PXO99 strain does not affect pathogenicity.

These results were also confirmed with bacterial growth in planta. To determine the multiplication of the PXO99 and PXO99 $9_{\mathrm{GFP}}$ strains in planta, the bacteria were recovered from infected rice leaves at 12 DAI, and dotted on PSA 
plates. Colonies were counted on PSA plates containing cephalexin or kanamycin, an antibiotic for selection of Xanthomonas spp. (Fig. 2B). Cephalexin is appreciated as an antibiotic for selection of Xanthomonas [25]. Populations of the susceptible lines of both PXO99 and PXO $99_{\text {GFP }}$ strains increased by $3.7 \times 10^{9}$ and $4.1 \times 10^{9}$, respectively, and both strains of the resistant lines increased by $3.2 \times 10^{7}$ and $2.7 \times 10^{7}$, respectively. These results indicate that expression of GFP in the bacterium, $X$. oryzae pv. oryzae, has no effect not only in the phenotypic symptom but also on bacterial growth in planta.

Bacteria have a tendency to lose exogenous plasmids in the absence of antibiotics [26]. We observed that pPneo$g f p$ in the PXO99 strain was not stable under non-selective conditions on PS medium without kanamycin (data not shown). Population increase was therefore measured on PSA plates containing cephalexin/kanamycin (PXO99 ${ }_{\mathrm{GFP}} \mathrm{Km}$ in Fig. $2 \mathrm{~B}$ ) to examine the stability of pPneo-gfp under host conditions (Fig. 2B). Surprisingly, the populations of the PXO99 $9_{\mathrm{GFP}}$ strain at 12 days did not vary with or without the kanamycin antibiotics, indicating that the pPneo-gfp plasmid is stable during propagation under host conditions. Recently, several reports showed similar phenomena that bacterial pathogens carry plasmid-borne fluorescent proteins in hosts. L. delbrueckii ssp. lactis and $L$. fructosus expressing GFP on plasmid in chickens allowed to trace it in the gastro-intestinal tract using fluorescence microscopy [15]. Another notable examples is $X$. axonopodis pv. dieffenbachiae strain containing p519ngfp plasmid [14]. This strain still showed and the fluorescence in the host, anthurium, even at 5 weeks after inoculation [14]. Taken together, although it is poorly understood why bacterial pathogens carry exogenous plasmids under host conditions, plasmid-borne GFP should be useful tool for tracing pathogen in the host.

In order to investigate if there is a difference in the disease progress between the PXO99 and PXO99 ${ }_{\mathrm{GFP}}$ strains, bacterial growth curves and lesion length development were established at 0, 4, 8, and 12 DAI [see Additional file 1]. Lesion lengths and bacterial populations at 4 and 8 DAI were nearly identical between the strains, indicating that the continuously expressed GFP did not affect disease progress. Tsuge, et al., reported that bioluminescent transconjugants of $X$. oryzae pv. oryzae were indistinguish-
A

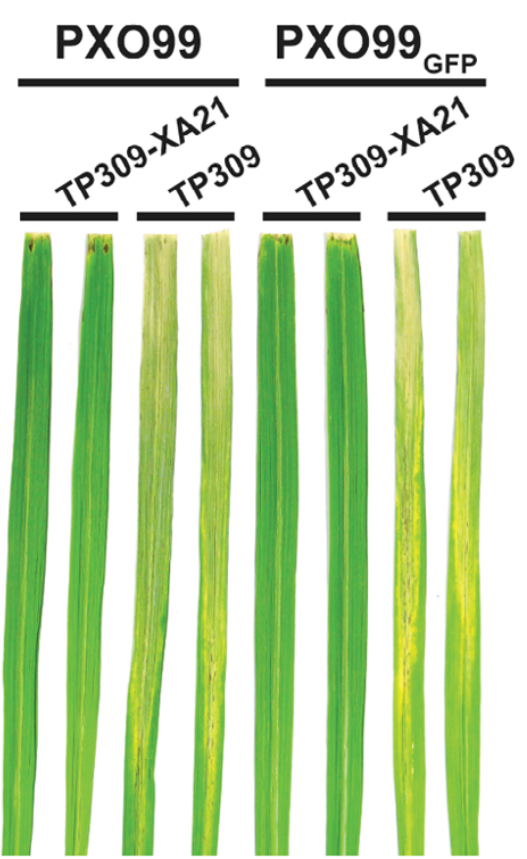

B

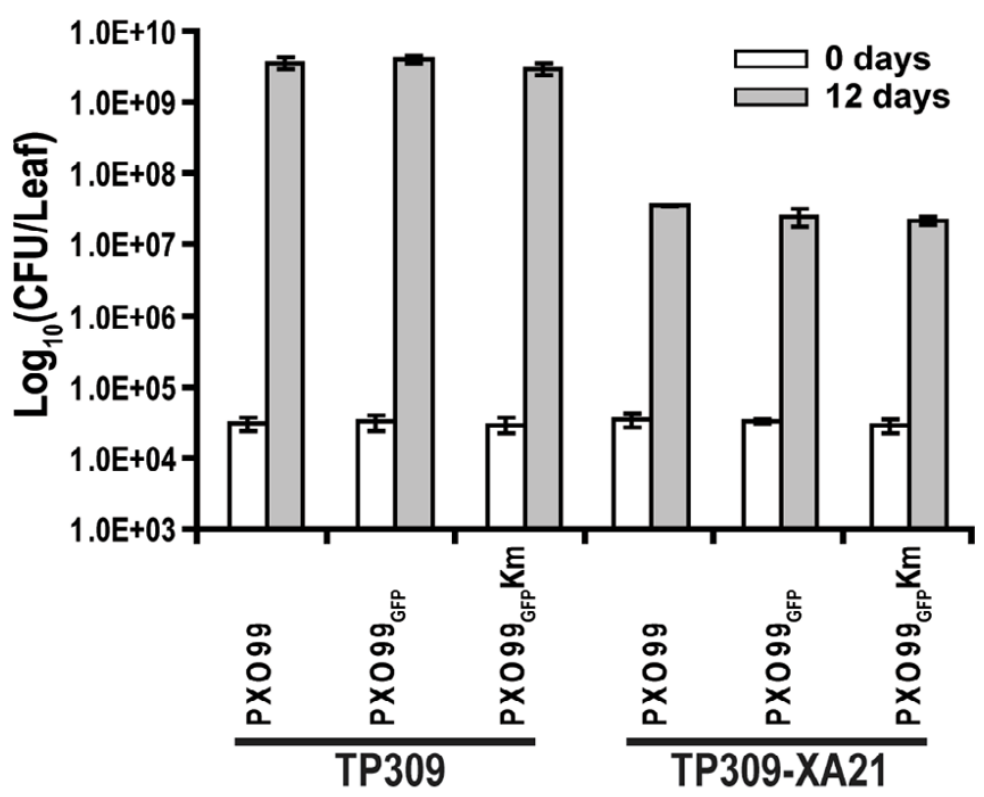

Figure 2

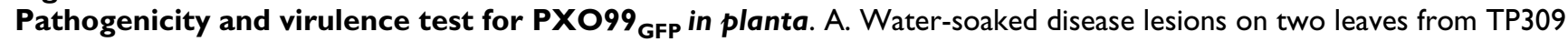
and TP309-XA2I at 12 days after PXO99 or PXO99 ${ }_{\text {GFP }}$ strains inoculation. B. After culture of PXO99 and PXO99 ${ }_{\text {GFP }}$ strains on PSA plates containing cephalexin, cells were diluted to $1.0 \times 10^{8} \mathrm{CFU} / \mathrm{ml}$, and then inoculated onto rice leaves of TP309 (susceptible) and TP309-XA2 I (resistant) lines using the scissor clipping method. Bacteria were recovered from the leaves at 0 (white bar) and 12 (grey bar) DAI and serially diluted, and then spread on PSA plates containing either cephalexin or cephalexin/kanamycin for colony counting. Each bar represents averages \pm standard deviation of three sampled leaves per treatment. The experiments were repeated three times with more than ten rice leaves from three individuals each time. $\mathrm{Km}$, kanamycin. 
able in pathogenicity with the parental strain [27]. To date, continuous fluorescence in bacteria did not alter the pathogenicity and virulence in the hosts. To apply our system with other patho-system, the stability of pPneo-gfp plasmid must be checked in planta growth.

We also confirmed the pathogenicity and virulence of the PXO99 $9_{\text {GFP }}$ strain and the stability of pPneo-gfp in the PXO99 $9_{\text {GFP }}$ strain using resistant and susceptible lines of Kitaake, another japonica cultivar, that has emerged as a model variety for rice genomics analysis [28]. The results from the Kitaake lines were consistent with the results from TP309 lines, showing that PXO99 $9_{\text {GFP }}$ strain had no detectable affect on the pathogenicity and virulence of the bacteria. These results suggest that the PXO99 ${ }_{\mathrm{GFP}}$ strain can be used with various cultivars. Taken together, our results indicate that the fluorescent $X$. oryzae $\mathrm{pv}$. oryzae PXO99 ${ }_{\mathrm{GFP}}$ strain with the pPneo-gfp plasmid is a useful tool for studies of pathogenesis.

\section{Visual observation of PXO99 GFP in planta}

We examined if the multiplication and colonization of bacteria can be visualized in rice leaf tissue. TP309 and TP309-XA21 were inoculated with the PXO99 $9_{\text {GFP }}$ strain, and then at 12 DAI a small segment of the leaf five centimetres down from the inoculation site was harvested. The leaf tissue was cut into segments with a razor blade, and the transverse sections of the leaf were observed under a fluorescent microscope (Fig. 3A and 3B). Fluorescence was detected at inoculation sites of both TP309 and TP309-XA21 (data not shown). As expected, no fluorescent signal was observed in the xylem of the TP309-XA21 lines at the site apart from infection sites since the PXO99 ${ }_{\mathrm{GFP}}$ strain could not spread through vascular systems in TP309-XA21 (Fig. 3B). On the other hand, the PXO99 $9_{\text {GFP }}$ strain propagated along vascular systems and was clearly observed in those of TP309 lines at the same position (Fig. 3A). These results demonstrate that the PXO99 ${ }_{\mathrm{GFP}}$ strain proliferated in the susceptible lines but not in resistant lines and that the difference can easily be detected using fluorescent microscopy. Our observation of PXO99 ${ }_{\text {GFP }}$ in the xylem is consistent with the findings of previous studies showing that $X$. oryzae pv. oryzae is a vascular pathogen $[2,3]$.

To test if PXO99 $9_{\text {GFP }}$ Xylem colonization is detectable at the leaf surface without using a thin section, we examined the surface of the leaf every five-centimetres from the inoculation site (Fig. 3C and 3D). The fluorescent PXO99 $9_{\mathrm{GFP}}$ strain was detected along the entire length of the leaf of susceptible TP309 lines in both vertical and transverse vascular bundles, even in symptomless regions that are 30 $\mathrm{cm}$ away from the inoculation site at 12 DPI (data not shown). However, the fluorescence from the PXO99 $9_{\mathrm{GFP}}$ strain in the resistant line, TP309-XA21, was not detected
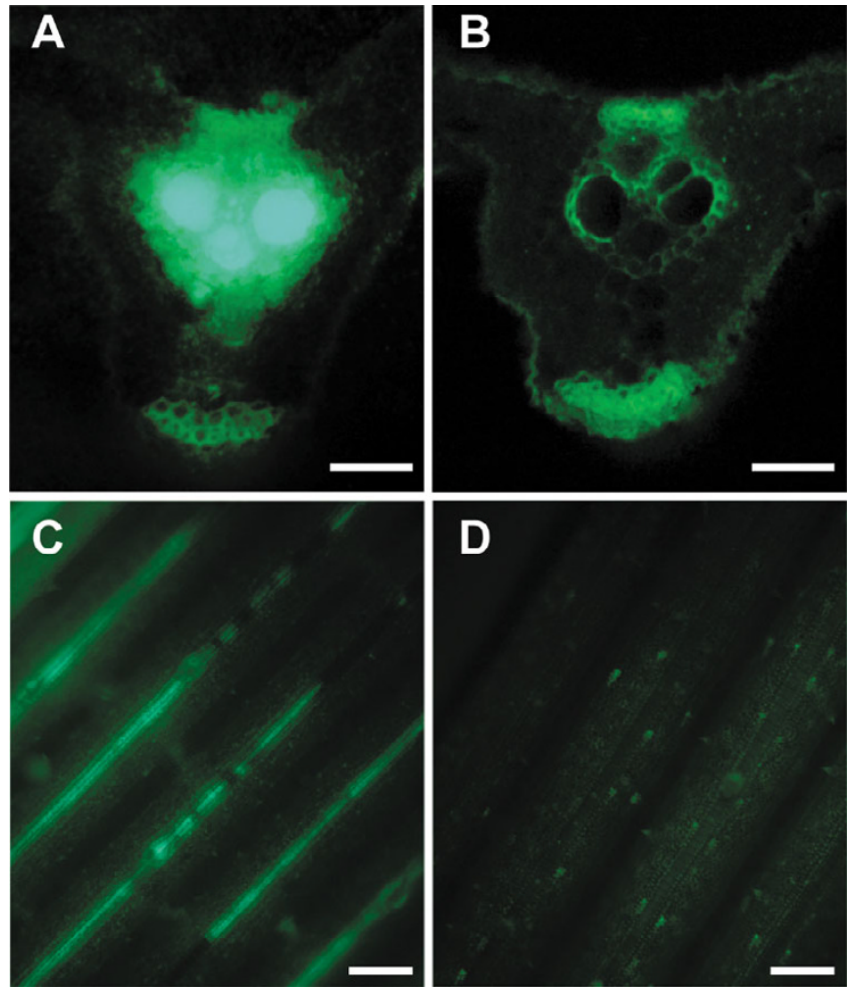

Figure 3

Visualization of $X$. oryzae pv. oryzae expressing GFP in planta. TP309 (A and C) and TP309-XA2I (B and D) were inoculated with $\mathrm{PXO} 99_{\mathrm{GFP}}$, harvested at $12 \mathrm{DAl}$, and then visualized under Zeiss Axiophot fluorescence microscope (Jena, Germany). Transverse sections ( $A$ and $B$ ) and leaf surface ( $C$ and $D)$ were observed with excitation from 450 to $490 \mathrm{~nm}$ and emitted light collected at $520 \mathrm{~nm}$ at $\times 40$ $(A$ and $B)$ and $\times 10(C$ and $D)$ magnification. Bars in $A$ and $B$, $50 \mu \mathrm{m}$. Bars in $C$ and $D, 10 \mu \mathrm{m}$.

even in the first five-centimeter region from inoculation site (Fig. 3D). This data shows that GFP can be used for efficient and rapid detection of $X$. oryzae pv. oryzae in planta. Additionally, we tested bacterial migration along vascular system in TP309 and TP309-XA21 lines at earlier time (4 DAI). Although lesion lengths were almost similar in both lines at $4 \mathrm{DAI}$, bacterial migrations were clearly different. PXO99 $9_{\text {GFP }}$ strain migrated $8.6 \mathrm{~cm}$ and $2.2 \mathrm{~cm}$ from inoculation sites in TP309 and TP309-XA21, respectively. These observations indicate that multiplication and localization of $X$. oryzae pv. oryzae in the rice vascular system occurs before typical disease symptoms, such as wilting and yellowing of leaf blades, can be detected [see Additional file 2]. In other words, although disease symptoms are not clearly apparent at 4 DPI [see Additional file 1], bacterial localization can be determined [see Additional file 2]. This result demonstrates that the PXO99 $9_{\text {GFP }}$ strain can be used to obtain an earlier diagnosis of infection compared to conventional methods. 
Quantification of PXO99 ${ }_{\text {GFP }}$ strain using a fluoremeter or enzyme-linked immunosorbent assay

To examine whether bacterial proliferation can be quantified using fluorescent microscopy, PXO99 wild type and PXO99 ${ }_{\mathrm{GFP}}$ cells were recovered from inoculated rice leaves and measured. Infection of PXO99 ${ }_{\mathrm{GFP}}$ was clearly different between susceptible and resistant rice lines (Fig. 4A). At 12 days after infection, the fluorescence dramatically increased from 983 at 0 days to 28,301 relative fluorescence units (RFU) in the susceptible line, TP309. In the resistant line, TP309-XA21, the fluorescence increased from 780 at day 0 to 7,009 RFU. The non-GFP strain, PXO99, also showed a low level of fluorescence that increased slightly by day 12 , which is attributed to (plant) auto-fluorescence and not GFP from a bacterial population. These results suggest that measurements of bacterial multiplication using the PXO99 $9_{\mathrm{GFP}}$ strain can replace the conventional colony counting method to screen for susceptible and resistant hosts.

The ELISA (enzyme-linked immunosorbent assay) is widely used to quantify a particular protein. This method has been applied as a diagnostic tool to detect specific pathogen proteins in medicine and plant pathology $[29,30]$. To quantify the multiplication of the PXO99 $9_{\text {GFP }}$ strain in rice, ELISA was carried out with anti-GFP antibody and the results were compared with the populations of the PXO99 $9_{\mathrm{GFP}}$ strain at the indicated time points (Fig. 4B). PXO99 and PXO99 ${ }_{\text {GFP }}$ strains were harvested from TP309 and TP309-XA21 at 0, 4, 8, and 12 DAI. While the PXO99 strain showed a background absorbance level at all time points (approximately $0.4 \mathrm{~A}_{480}$ (absorbance at $480 \mathrm{~nm})$ ), the PXO99 $9_{\mathrm{GFP}}$ strain showed a temporaldependent increase of GFP. The level of GFP expression in the resistant rice line was maintained with a gentle increase until 12 DAI. Interestingly, the GFP in the susceptible rice line, TP309, increased after 4 DAI and reached up to $2.0 \mathrm{~A}_{480}$ at $12 \mathrm{DAI}$. This increase of GFP observed in ELISA correlated well with PXO99 $9_{\mathrm{GFP}}$ population levels (inset in Fig. 4B), indicating that the significant increase of GFP in rice is dependent on bacterial multiplication. Because the fluorescent marker approach does not require diluting, incubating, and counting of bacterial cells, the method is 3 days faster than conventional measurement methods using plate assays. Taken together, these results suggest that measurement of the bacterial fluorescence and GFP quantification by ELISA are sensitive and rapid methods to determine growing bacterial population and host resistance compared to conventional methods.

\section{Conclusion}

In this report, we introduce an application of a fluorescent marker system for study of the phytopathogenic bacterium, $X$. oryzae pv. oryzae. The fluorescent $X$. oryzae pv. oryzae strain, $\mathrm{PXO} 99_{\mathrm{GFP}}$, facilitates detection of the invad-
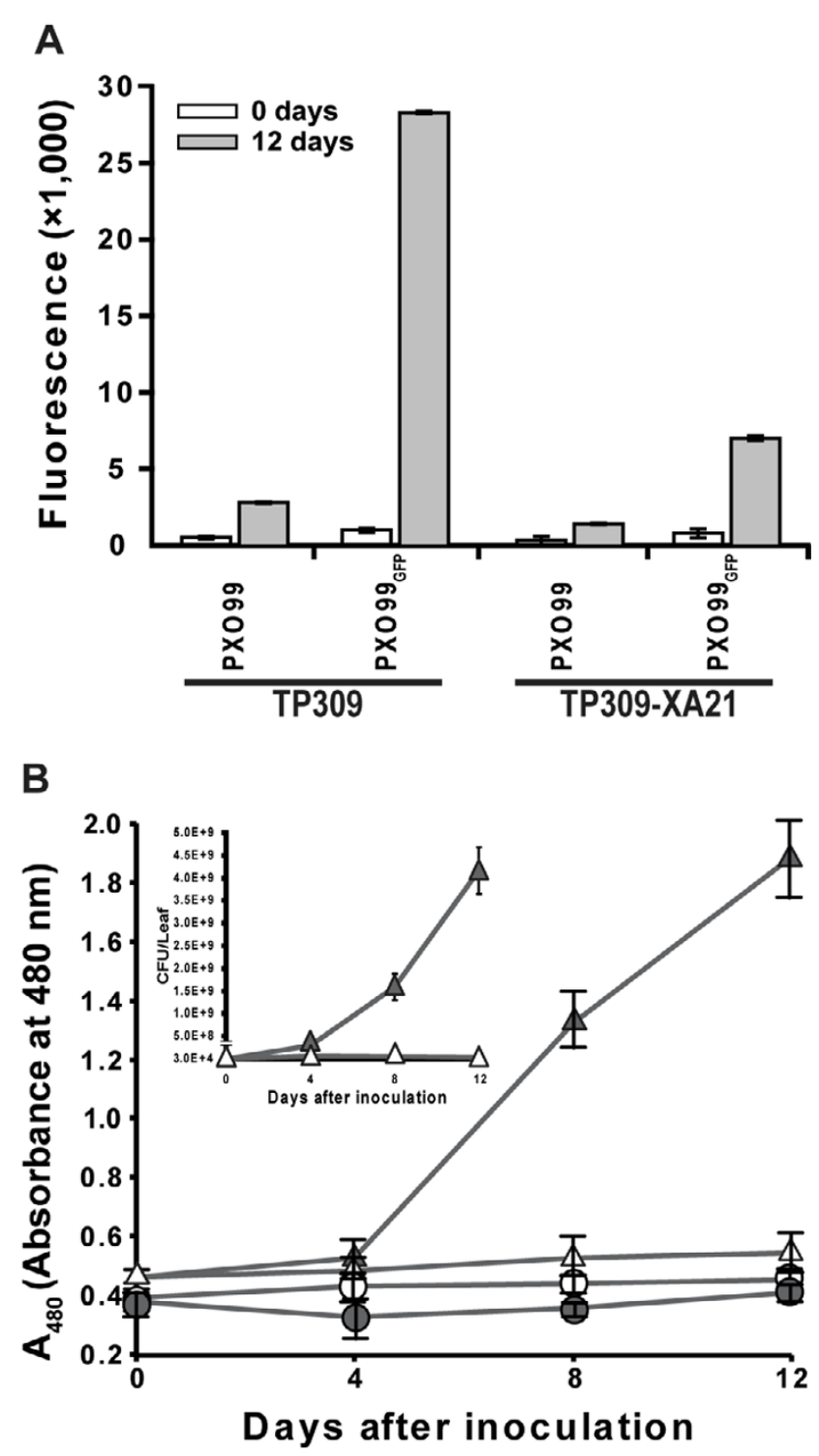

Figure 4

Quantification of PXO99 ${ }_{\text {GFP }}$ expressing GFP using a fluoremeter or ELISA. A. Fluorescence of the bacteria recovered from the rice leaves was directly measured with a fluoremeter (excitation, $480 \mathrm{~nm}$; emission, $520 \mathrm{~nm}$ ). The bars indicate average of the fluorescence of each sample and the error bars are standard deviations from six technical replicates of two biological replicates. B. GFP protein expressed in $\mathrm{PXO} 99_{\mathrm{GFP}}$ under host condition were quantified using ELISA, Inoculated bacterial strains, PXO99 (circle) and PXO99 ${ }_{\text {GFP }}$ (triangle), were recovered from the scored rice leaves of TP309 (close) and TP309-XA2I (open) at 0, 4, 8, and I 2 DAI. ELISA using anti-GFP polyclonal IgG antibody then carried out. Each value represents averages of the absorbance at $480 \mathrm{~nm}$ and standard deviation from three leaves per treatment. Inset is the bacterial growth curve with linear scale. This experiment was repeated three times with more than ten rice leaves. 
ing pathogen. With this fluorescent marker system, bacterial population can be measured in a day, and resistant/ susceptible lines can be screened at 4 DPI. This application, which may be used for other patho-systems, can reduce the time and effort required for bacterial growth determination compared to the conventional method.

\section{Methods}

\section{Bacteria strains, plants and growth conditions}

Xanthomonas oryzae pv. oryzae Philippine race 6 (PXO99Az kindly provided by Jan Leach and called PXO99 in this study) was used for this study [31]. The bacteria strains and plasmids used in this study are listed in Table 1. Peptone sucrose media [32] containing cephalexin $(20 \mu \mathrm{g} /$ $\mathrm{ml})$ (MP Biomedicals, USA) or cephalexin $(20 \mu \mathrm{g} / \mathrm{ml}) /$ kanamycin $(50 \mu \mathrm{g} / \mathrm{ml})$ were used for growing cultures of PXO99 or PXO99 ${ }_{\mathrm{GFP}}$ at $28^{\circ} \mathrm{C}$, respectively. Escherichia coli strains were cultured in Luria-Bertani (LB) medium at $37^{\circ} \mathrm{C}$. For E. coli, kanamycin at $50 \mu \mathrm{g} / \mathrm{ml}$, ampicillin at $100 \mu \mathrm{g} / \mathrm{ml}$ or gentamycin at $25 \mu \mathrm{g} / \mathrm{ml}$ were used for selection of transformants.

For inoculation experiments to test for virulence, two different cultivars of the japonica rice varieties Taipei 309 (TP309) and Kitaake (Kit) were used. Transgenic mutant lines of the cultivars expressing XA21 protein, TP309XA21 and Kit-XA21, that are resistant to PXO99 strain expressing AvrXA21 [33] were used for avirulence test. The surface was sterilized in 95\% ethanol for $5 \mathrm{~min}, 40 \%$ bleach for 30 min with shaking and then three times rinsed with sterilized water. Rice seeds were germinated for three or four days in water at $37^{\circ} \mathrm{C}$ in water. The germinated seeds were planted onto soil and grown in greenhouse. Six-week-old rice for TP309 line and five-week-old rice for Kit lines were transferred into growth chamber at least two day prior to inoculation. The growth chamber was set on a $16 \mathrm{~h}$ light and $8 \mathrm{~h}$ dark photoperiod, a 28/ $26^{\circ} \mathrm{C}$ temperature cycle, and $90 \%$ humidity.

\section{Molecular techniques}

Standard methods described in Sambrook et al. [34] were used for DNA manipulations during plasmid preparations and digestions with restriction enzymes. All enzymes for construction of plasmid were purchased from Invitrogen. DNA and protein concentrations were measured using the Nanodrop ${ }^{\circledR}$ ND-1000 (Bio-Rad, USA). The Cell-Porator $^{\mathrm{TM}}$ system (Gibco BRL, USA) was used for $E$. coli ( $\geq 600$ DC) and X. oryzae pv. oryzae ( $\geq 700$ DC) transformations under the following conditions; booster: 4 , capacitance: $330 \mu \mathrm{F}$, charge rate: fast, low $\alpha$.

\section{Generation of Xanthomonas oryzae pv. oryzae mutant strain carrying green fluorescent protein (gfp) gene}

Broad-host-range promoterless probe vector, pPROBE-gfp [20], was used for generation of $X$. oryzae pv. oryzae mutant strain constitutively expressing GFP. Neomycin promoter (approximately 400 nucleotide-lengths) cut out with Sal I and EcoR I from pML122 vector [21] was inserted into the multi-cloning site of the pPROBE-gfp vector linearized with the same enzymes. The construct for constitutively expressing GFP, pPneo-gfp, was introduced into E. coli competent cell, DH10B, and then selected on the LB plates containing $50 \mu \mathrm{g} / \mathrm{ml}$ of kanamycin. The plasmid DNA extracted from the E. coli transformants re-introduced into PXO99 competent cells using electroporation method. The PXO99 mutant strain carrying the pPneo-gfp was $\left(\mathrm{PXO}_{\mathrm{GFP}}\right)$ selected on the PSA plates containing $20 \mu \mathrm{g} / \mathrm{ml}$ of cephalexin and $50 \mu \mathrm{g} / \mathrm{ml}$ of kanamycin. The transformants also confirmed by observation using a Zeiss Axiophot fluorescence microscope (Jena, Germany) equipped with a fluorescein isothiocyanate filter (excitation filter, 450 to $490 \mathrm{~nm}$; emission filter, $520 \mathrm{~nm}$; dichroic mirror, $510 \mathrm{~nm}$ ).

\section{Inoculation experiment and bacteria growth in planta}

$X$. oryzae pv. oryzae strains were prepared by culturing on PSA plates containing either cephalexin (for the PXO99)

Table I: Bacterial strains and plasmids used in this study

\begin{tabular}{|c|c|c|}
\hline Strain or plasmid & Relevant characteristics & Source or reference \\
\hline \multicolumn{3}{|l|}{ Escherichia coli } \\
\hline $\mathrm{DHIOB}$ & $\begin{array}{l}\text { F-mcrA } \Delta \text { (mrr-hsdRMS-mcrBC) } \phi 80 / a c Z \Delta M I 5 \Delta / a c X 74 \text { deoR recAl endAI ara } \Delta I 39 \Delta \text { (ara, } \\
\text { leu)7687galU galK } \lambda r p s L(S p r) n u p G \lambda \text { tonA }\end{array}$ & Gibco BRL \\
\hline \multicolumn{3}{|c|}{ Xanthomonas oryzae pv. oryzae } \\
\hline PXO99 & Philippine race 6 (PR6) strain, $C p^{r}$ & {$[31]$} \\
\hline $\mathrm{PXO99}$ GFP & PXO99 with pPROBE-NTpNm, $\mathrm{Km}^{r}, \mathrm{Cp}^{r}$ & This study \\
\hline \multicolumn{3}{|l|}{ Plasmids } \\
\hline PPROBE-gfp & pBBRI ori, $\mathrm{Km}^{\mathrm{r}}$, broad-host range expression vector & {$[20]$} \\
\hline pPneo-gfp & neo (promoter of neomycin resistant gene) cloned into pPROBE-gfp & This study \\
\hline PMLI 22 & OriV, OriT, Gm , pNm (nptll), broad-host range expression vector & {$[21]$} \\
\hline
\end{tabular}

$C p^{r}$ : Cephalexin resistance, Spr: Spectinomycin resistance, $\mathrm{Km}^{\mathrm{r}}$ : Kanamycin resistance, $\mathrm{Gm}^{\mathrm{r}}$ : Gentamycin resistance 
or cephalexin/kanamycin (for the PXO99 ${ }_{\mathrm{GFP}}$ ) for three days at $28^{\circ} \mathrm{C}$. Rice leaves were inoculated with the scissor clipping method [24], using cells suspended in distilled water at a density approaching $1.0 \times 10^{8} \mathrm{CFU} / \mathrm{ml}$. Lesion lengths were measured $0,4,8$, and $12 \mathrm{DAI}$.

$X$. oryzae pv. oryzae growth in planta was measured using a modified method from a report by Song et al. [33]. For establishing growth curves, the inoculated rice leaves were harvested at each time point, immediately sliced into small pieces. Sliced rice leaves were incubated in $1 \mathrm{ml}$ sterile water including $15 \mu \mathrm{g} / \mathrm{ml}$ of cephalexin with shaking for $1 \mathrm{~h}$, and then filtered through two layers of cheesecloth. The filtrates were then plated onto PSA plates with cephalexin for PXO99 strain or cephalexin/kanamycin for PXO99 $9_{\mathrm{GFP}}$ strain. Colonies on the plates were counted after three days of incubation at $28^{\circ} \mathrm{C}$.

\section{Microscope}

To visualize bacterial infection through leaf veins under microscope, rice leaves were harvested at 12 DAI. To get thin transverse sections $(0.1 \mathrm{~mm})$, TP309 and TP309XA21 leaves inoculated with PXO99 $9_{\mathrm{GFP}}$ were cut using a razor blade. The small pieces of leaf sections were placed on a microscope slide, submerged in immersion oil (Cargille lab, USA), covered with a glass slip and sealed with grease. The fluorescence photographs were taken using a Zeiss Axiophot fluorescence microscope (Jena, Germany) fitted with fluorescein isothiocyanate filters (excitation filter, 450 to $490 \mathrm{~nm}$; emission filter, $520 \mathrm{~nm}$; dichroic mirror, $510 \mathrm{~nm}$ ). The optimal exposure time was 1 sec. Three biological replicates using leaf blades from each of the three different plants were used for all microscopic analyses.

\section{Fluorimetric measurements of PXO99 ${ }_{\text {GFP }}$ strain}

$X$. oryzae pv. oryzae strains were inoculated on 6 weeks old TP309 and TP309-XA21 lines, and to quantify GFP using a fluoremeter, $X$. oryzae pv. oryzae cells were recovered at 0 , and 12 DPI as described in the previous section. The bacteria recovered from the rice leaves were serially diluted until $10^{-4}$ with water and $200 \mu$ l of cell suspension were transferred in a microtitre plate, MICROTEST ${ }^{\text {тм }} 96$ (Falcon, USA). Fluorescence of the bacteria was directly measured in a fluoremeter, SafireII (Tecan, USA) [35]. GFP fluorescence was measured at a wavelength of 480 $\mathrm{nm}$ for excitation and $520 \mathrm{~nm}$ for emission, with a bandwidth of $20 \mathrm{~nm}$ in both cases.

\section{Enzyme-Linked ImmunoSorbant Assay}

Leaves were collected from TP309 and TP309-XA21 at 0, 4,8 , and 12 DAI by PXO99 or PXO99 $9_{\mathrm{GFP}}$ strain. The inoculated rice leaves were harvested at each time point, immediately sliced into small pieces, incubated in $1 \mathrm{ml}$ sterile water including $15 \mu \mathrm{g} / \mathrm{ml}$ of cephalexin with shak- ing for $1 \mathrm{~h}$, and then filtered through two layers of cheesecloth. The filtrates were precipitated by centrifugation at $15,000 \mathrm{~g}$ for $15 \mathrm{~min}$, and the pellets were dissolved in 100 $\mu \mathrm{l}$ of lysis buffer (100 mM Tris-Cl, pH 8.0, $8 \mathrm{M}$ urea, and $100 \mathrm{mM} \mathrm{NaH}_{2} \mathrm{PO}_{4}$ ). Micro-ELISA plates (96-well plate, Fisher Scientific, UK) were coated with $200 \mu \mathrm{l}$ of PXO99 or PXO99 $9_{\text {GFP }}$ diluted with carbonate-bicarbonate buffer (0.2 M sodium carbonate-bicarbonate, pH9.4). After overnight incubation at $4^{\circ} \mathrm{C}$, plates were washed three times with $0.5 \%$ Tween-20 in PBS buffer $(10 \mathrm{mM}$ phosphate buffer, $\mathrm{pH} 7.4,150 \mathrm{mM} \mathrm{NaCl}$, and $0.1 \%$ sodium azide; PBST). Plates were treated with 5\% skim milk in PBS and washed three times with PBST buffer. Anti-GFP polyclonal IgG antibody (Santa cruz, USA) of 1:500 dilution was added to each well $(100 \mu \mathrm{l} /$ well $)$ and incubated for $1 \mathrm{~h}$ at $37^{\circ} \mathrm{C}$. After three washings with PBST, a 1: 5,000 diluted horseradish peroxidase linked anti-rabbit IgG antibody (GE healthcare, UK) was added for $1 \mathrm{~h}$ at $37^{\circ} \mathrm{C}$. The plates were subsequently washed three times with PBST. To detect peroxidase activity, one OPD (orthophylenediamine) tablet (Sigma, USA) and one urea hydrogen peroxidase tablet (Sigma, USA) was dissolved in $20 \mathrm{ml}$ of distilled water. $200 \mu \mathrm{l}$ of substrate was added to each well and incubate the plate in the dark for $20 \mathrm{~min}$ at room temperature followed by addition of $50 \mu \mathrm{l} 3 \mathrm{M} \mathrm{HCl}$ to stop the reaction. Absorbance of the plate was measured at $480 \mathrm{~nm}$ by an ELISA reader, SafireII (Tecan, USA).

\section{Ethics}

Exempt - animal subjects are not used.

\section{Competing interests}

The authors declare that they have no competing interests.

\section{Authors' contributions}

SWH carried out inoculation experiments including lesion measurement, bacterial growth curve with conventional method, and recovery of bacterial cells and proteins for ELISA and fluorescence. CJP carried out microscope observation and ELISA. SWL generate all bacterial strains for this study and measured fluorescence. SWH, CJP, SWL, and PCR participated in its design and coordination and helped to draft the manuscript. All authors read and approved the final manuscript. 


\section{Additional material}

\begin{abstract}
Additional file 1
Comparison of disease progress in TP309 and TP309-XA21 by inoculation of PXO99 and PXO99GFP. A. Lesion lengths of PXO99 (circle) and PXO99GFP (triangle) inoculated plants, TP309 (closed) and TP309-XA21 (opened). Each data represents the average and standard deviation that were established from more than ten leaves. B. Plots of PXO99 (circle) and PXO99GFP (triangle) populations at 0, 4, 8, and 12 DAI in TP309 (closed) and TP309-XA21 (opened). Cultured PXO99 and PXO99GFP strains were diluted to $1.0 \times 10^{8} \mathrm{CFU} / \mathrm{ml}$ and then inoculated to TP309 and TP309-XA21 rice leaves using scissor clipping method respectively. The data in each time point were calculated from three leaves and repetition three times.

Click here for file

[http://www.biomedcentral.com/content/supplementary/14712180-8-164-S1.tiff]

\section{Additional file 2}

Measurements of bacterial migration and lesion length in TP309 and TP309-XA21 by inoculation of PXO99GFP strain at 4 DAI. After culture of PXO99GFP strain on PSA plates containing cephalexin/kanamycin, cells were diluted to $1.0 \times 10^{8} \mathrm{CFU} / \mathrm{ml}$, and then inoculated onto rice leaves of TP309 (susceptible) and TP309-XA21 (resistant) lines using the scissor clipping method. Bacterial migration (grey bar) and lesion length (white bar) were measured from inoculation sites at 4 DAI. Fluorescent bacteria in collected samples were observed with microscope equipped with a fluorescein isothiocyanate filter (excitation filter, 450 to $490 \mathrm{~nm}$; emission filter, $520 \mathrm{~nm}$; dichroic mirror, $510 \mathrm{~nm}$ ). Each bar represents averages \pm standard deviation. The experiments were repeated three times with more than ten rice leaves from three individuals each time.

Click here for file

[http://www.biomedcentral.com/content/supplementary/14712180-8-164-S2.tiff]
\end{abstract}

\section{Acknowledgements}

We thank Dawn Chiniquy for helpful comments and critical reading of the manuscript. This work was financially supported by USDA grants \# 200601888, \# 2007-01531, and USDA Rice CAP. The work of S.-W. H. was partially supported by a grant for the Graduate Study Abroad Scholarship from the Korean Science and Engineering Foundation. The work of C.-J. P. was partially supported by grant for the Post-doctoral Fellowship Program of Korea Science \& Engineering Foundation.

\section{References}

I. Ou SH: Rice Diseases. Aberystwyth, England: Commonwealth Micrological Institute; 1985:70-74.

2. Niño-Liu DO, Ronald PC, Bogdanove AJ: Xanthomonas oryzae pathovars: model pathogens of a model crop. Molecular Plant Pathology 2006, 7:303-324.

3. Mew TW: Xanthomonas oryzae pathovars on rice: cause of bacterial blight and bacteria leaf streak. London: Chapman \& Hall; 1993.

4. OEPP/EPPO: Xanthomonas oryzae. EPPO Bulletin 2007, 37(3):543-553.

5. Shimomura O, Johnson $\mathrm{FH}$, Saiga $\mathrm{Y}$ : Extraction, purification and properties of aequorin, a bioluminescent protein from the luminous hydromedusan, Aequorea. J Cell Comp Physiol 1962, 59:223-239.

6. Hillesheim LN, Muller JD: The Dual-Color Photon Counting Histogram with Non-Ideal Photodetectors. Biophys J 2005, 89(5):349I-3507.
7. Mizuno H, Sawano A, Eli P, Hama H, Miyawaki A: Red Fluorescent Protein from Discosoma as a Fusion Tag and a Partner for Fluorescence Resonance Energy Transfer. Biochemistry 200I, 40(8):2502-25I0

8. Caplan JL, Mamillapalli P, Burch-Smith TM, Czymmek K, DineshKumar SP: Chloroplastic Protein NRIPI Mediates Innate Immune Receptor Recognition of a Viral Effector. Cell 2008, I32(3):449-462.

9. Margolin W: Green fluorescent protein as a reporter for macromolecular localization in bacterial cells. Methods 2000 , 20(I):62-72.

10. Berg RH, Beachy RN, Kevin FS: Fluorescent Protein Applications in Plants. In Methods in Cell Biology Volume 85. Academic Press; 2008:153-177.

II. Tsien RY: THE GREEN FLUORESCENT PROTEIN. Annual Review of Biochemistry 1998, 67(I):509-544.

12. Bracha-Drori K, Shichrur K, Katz A, Oliva M, Angelovici R, Yalovsky $\mathrm{S}$, Ohad N: Detection of protein-protein interactions in plants using bimolecular fluorescence complementation. Plant J 2004, 40(3):419-427.

13. Chun W, Waldo GS, Johnson GVW: Split GFP complementation assay: a novel approach to quantitatively measure aggregation of tau in situ: effects of GSK3; activation and caspase 3 cleavage. Journal of neurochemistry 2007, 103(6):2529-2539.

14. Elibox W, Umaharan P: A green fluorescent protein-based screening method for identification of resistance in anthurium to systemic infection by Xanthomonas axonopodis pv. dieffenbachiae. Plant Pathology 2007, 56(5):819-827.

15. Yu Q-H, Dong S-M, Zhu W-Y, Yang Q: Use of green fluorescent protein to monitor Lactobacillus in the gastro-intestinal tract of chicken. FEMS Microbiology Letters 2007, 275(2):207-2I3.

16. Fan J, Crooks C, Lamb C: High-throughput quantitative luminescence assay of the growth in planta of Pseudomonas syringae chromosomally tagged with Photorhabdus luminescens luxCDABE. The Plant Journal 2008, 53(2):393-399.

17. Newman KL, Almeida RP, Purcell AH, Lindow SE: Use of a green fluorescent strain for analysis of Xylella fastidiosa colonization of Vitis vinifera. Appl Environ Microbiol 2003, 69(12):7319-7327.

18. Tornero P, Dangl JL: A high-throughput method for quantifying growth of phytopathogenic bacteria in Arabidopsis thaliana. The Plant Journal 200I, 28(4):475-48I.

19. Whalen MC, Innes RW, Bent AF, Staskawicz BJ: Identification of Pseudomonas syringae pathogens of Arabidopsis and a bacterial locus determining avirulence on both Arabidopsis and soybean. Plant Cell I99I, 3:49-59.

20. Millar WG, Leveau JH, Lindow SE: Improved gfp and inaZ Broadhost-range promoter-probe vectors. Mol Plant Microbe Interact 2000, I3( I I): I 243-1250.

21. Labes M, Puhler A, Reinhard S: A new family of RSF I O I 0-derived expression and lac-fusion broad-host-range vectors for Gram-negative bacteria. Gene 1990, 89:37-46.

22. Newman KL, Almeida RP, Purcell AH, Lindow SE: Cell-cell signaling controls Xylella fastidosa interactions with both insects and plants. Proc Natl Acad Sci USA 2004, I 0 I(6): I 737- 1742.

23. Lee SW, Jeong KS, Han SW, Lee SE, Phee BK, Hahn TR, Ronald P: The Xanthomonas oryzae pv. oryzae PhoPQ Two-Component System Is Required for AvrXA2 I Activity, hrpG Expression, and Virulence. J Bacteriol 2008, 190(6):2183-2197.

24. Kauffman HE, Reddy APK, Hsieh SPY, Merca SD: An improved technique for evaluating resistance of rice varieties to Xanthomonas oryzae. Plant Dis Rep 1973, 57:537-54I.

25. Juhnke ME, des Jardin E: Selective medium for isolation of Xanthomonas maltophilia from soil and rhizosphere environments. Appl Environ Microbiol 1989, 55(3):747-750.

26. Smith MA, Bidochka MJ: Bacterial fitness and plasmid loss: the importance of culture conditions and plasmid size. Can J Microbiol 1998, 44(4):35I-355.

27. Tsuge S, Ikawa $Y$, Hikichi $Y$, Nakazawa-Nasu $Y$, Suzuki K, Kubo $Y$, Horino O: Behavior of Bioluminescent Transconjugants of Xanthomonas oryzae pv. oryzae in Compatible and Incompatible Rice Leaves. Xanthomonas oryzae 1999, 65:93-99.

28. Jung K-H, An G, Ronald PC: Towards a better bowl of rice: assigning function to tens of thousands of rice genes. Nat Rev Genet 2008, 9(2):91-101. 
29. Lequin RM: Enzyme Immunoassay (EIA)/Enzyme-Linked Immunosorbent Assay (ELISA). Clin Chem 2005, 5 I(I2):24I5-24I8.

30. van Weemen $B K$, Schuurs $A H$ : Immunoassay using antigen enzyme conjugates. FEBS Letters I97I, I5(3):232-236.

31. Hopkins CM, White FF, Choi SH, Guo A, Leach JE: Identification of a family of avirulence genes from Xanthomonas oryzae pv. oryzae. Mol Plant Microbe Interact 1992, 5:45 I-459.

32. Tsuchiya K, Mew TM, Wakimoto S: Bacteriological and pathological characteristics of wild types and induced mutants of Xanthomonas campestris pv. oryzae. Phytopathology 1982, 72:43-46.

33. Song W, Wang G, Chen L, Kim H, Pi L, Holsten T, Gardner J, Wang $B$, Zhai W, Zhu L, et al: A receptor kinase-like protein encoded by the rice disease resistance gene, Xa2I. Science 1995 , 270(5243): | 804- I806.

34. Sambrook J, Fritsch EF, Maniatis T: Molecular Cloning: a Laboratory Manual. New York: Cold Spring Harbor Laboratory Press; 1989.

35. Kaffarnik F, Muller P, Leibundgut M, Kahmann R, Feldbrugge M: PKA and MAPK phosphorylation of PrfI allows promoter discrimination in Ustilago maydis. Embo J 2003, 22(21):5817-5826.

Publish with Biomed Central and every scientist can read your work free of charge

"BioMed Central will be the most significant development for disseminating the results of biomedical research in our lifetime. "

Sir Paul Nurse, Cancer Research UK

Your research papers will be:

- available free of charge to the entire biomedical community

- peer reviewed and published immediately upon acceptance

- cited in PubMed and archived on PubMed Central

- yours - you keep the copyright

Submit your manuscript here:

http://www.biomedcentral.com/info/publishing_adv.asp 